\title{
Alloying colloidal silver nanoparticles with gold disproportionally controls antibacterial and toxic effects
}

\author{
Sebastian Grade • Jörg Eberhard • Jurij Jakobi • \\ Andreas Winkel • Meike Stiesch • Stephan Barcikowski
}

Published online: 17 November 2013

(C) The Author(s) 2013. This article is published with open access at SpringerLink.com

\begin{abstract}
Elemental silver nanoparticles are an effective antibacterial substance and are found as additive in various medical applications. Gold nanoparticles are used due to their optical properties in microscopy and cancer therapy. These advantages might be combined within alloyed nanoparticles of both elements and thereby open new fields of interest in research and medical treatment. In this context, laser ablation of solid alloys in liquid gives access to colloidal silver-gold alloy nanoparticles with a homogeneous ultrastructure. Elemental and alloy silver-gold nanoparticles with increasing molar fractions of silver $(50,80$, and $100 \%)$ were produced and stabilized with citrate or albumin (BSA). Particles were embedded in agar at concentrations of 3-100 $\mathrm{g} \mathrm{cm}^{-3}$ and tested on clinical relevant Staphylococcus aureus regarding their antibacterial properties. Cytotoxic effects were measured within the same particle concentration range using human gingival fibroblasts (HGFib). As expected, a reduced fraction of silver in the nanoalloys decreased the antibacterial effect on $S$. aureus according to the evaluated minimal inhibitory concentrations. However, this decrease turned out stronger than expected by its relative mass per particle, due to the electrochemical, disproportionally high effect of gold on the bioresponse to silver within silver-gold nanoalloy particles.
\end{abstract}

Electronic supplementary material The online version of this article (doi:10.1007/s13404-013-0125-6) contains supplementary material, which is available to authorized users.

S. Grade $(\bowtie) \cdot$ J. Eberhard $\cdot$ A. Winkel $\cdot$ M. Stiesch

Department of Prosthetic Dentistry and Biomedical Materials

Science, Hannover Medical School, Carl-Neuberg-Straße 1,

30625 Hannover, Germany

e-mail: grade.sebastian@mh-hannover.de

J. Jakobi $\cdot$ S. Barcikowski ( $\bowtie)$

Technical Chemistry I; University of Duisburg-Essen and Center for

Nanointegration Duisburg-Essen (CENIDE), Universitaetsstrasse 7,

45141 Essen, Germany

e-mail: stephan.barcikowski@uni-due.de
BSA was able to stabilize all colloids and maintain antibacterial activity, whereas sodium citrate reduced antibacterial effects and cytotoxicity even at high nanoparticle concentrations. The alloying of silver with gold by laser ablation in liquid produced nanoparticles with both reduced antibacterial and cytotoxic properties in comparison to silver nanoparticles but still retains the application spectrum of both elements combined in one colloid. In particular, alloying with gold may render silver nanoparticles more biocompatible, and allows bioconjugation via established thiol chemistry.

Keywords $\mathrm{AgAu} \cdot$ nanotoxicology $\cdot$ antibacterial · nanocolloids

\section{Introduction}

Alloying of metals has been established for centuries in material science and metallurgy, aiming at the optimization of material properties and functionality. Multifunctional materials attract a lot of attention in the rapid developing field of nanotechnology. Investigation and integration of new materials can facilitate new approaches, e.g., in the biomedical field. For such applications materials like silver and gold have already been investigated for years and it is well known that elemental silver releases ions [1], whereas gold is known for its optical properties and adsorption of proteins [2,3]. Combining both elements in one material, in particular within a nanoparticle, might cause a synergetic effect of the properties and thereby provide an access to new materials with new application possibilities. For example, the use of silver in combination with gold could open new possibilities for the conjugation of antibacterial silver nanoparticles to various thiolated biomolecules via covalent bonding to gold atoms.

Due to their antibacterial properties, silver nanoparticles are increasingly used in different medical applications including antimicrobial coatings or wound dressings $[1,4,5]$. Silver 
reduces bacterial growth by releasing silver ions, which inhibit enzymatic activity and destroy protein structures on bacterial cell membranes [6, 7]. Silver nanoparticles used in antibacterial implant coatings and surfaces are often embedded in composites or hydrogels, which release the silver ions over time to the adjacent area $[8,9]$. Unfortunately, high concentrations of antibacterial silver ions also exhibit cytotoxic effects on eukaryotic cells, making it difficult to establish a possible therapeutic window [10-12]. The cytotoxic effects of silver nanoparticles on eukaryotic cells are described in many studies and the particle concentrations, which cause at least moderate cytotoxicity depend very much on the type of cells used [13-16]. The influence of chemicals, added after (surfactants) or during (reducing agents and capping ligands) nanoparticle synthesis on the silver ion release is an additional factor, which can change the antibacterial and cytotoxic effects of silver. For instance, when bovine serum albumin is added to freshly synthesized, ligand-free silver particles, it significantly reduces the antibacterial effect on different species of bacteria [17].

Gold nanoparticles display only very low cytotoxic effects on eukaryotic cell in comparison to silver $[16,18,19]$. They are known for their strong binding affinity to bovine serum albumin, commonly used as stabilizing agent [20-22] and are responsible for the formation of a protein corona on nanoparticle surfaces [23, 24]. It could be assumed that different gold molar fractions in silver-gold alloy nanoparticles change the binding affinity of BSA to these particles subsequently influencing ion release. Regarding ion release, bimetallic alloys show physical and chemical properties very different from their separate monometallic components [25].

Without using any chemical precursors, ligand-free colloidal nanoparticles can be produced by laser ablation of solid targets in liquids [26, 27]. Hence, toxicological analysis of laser-generated colloids reveals toxicity only for nanoparticles and not for residual chemicals [28, 29], like it is the case with chemically prepared colloids $[30,31]$. This method enables ablation of different alloy materials, especially if the targets consist of fully miscible elements such as $\mathrm{Ag}$ and $\mathrm{Au}$, or $\mathrm{Pt}$ and Ir [32-34]. The availability of any desired $\mathrm{Ag} / \mathrm{Au}$ ratio in a solid alloy, in combination with its ablation in liquid by lasers, gives access to colloidal alloy nanoparticles with defined compositions [35, 36]. Since it has been recently shown that gold-silver nanoparticle surface patterns designed from co-sputtering of gold with silver showed a silver ion release disproportional to the silver content in the alloy, the question arises whether this effect will also be observed in the bioresponse to nanoparticles [37, 38].

The objective of this study was to understand the biological behavior to the combination of bioactive, ion-releasing silver and noble, protein-adsorbing gold in one nanocolloid. The antibacterial and cytotoxic effects on bacteria and cells for different ratios of gold and silver within the particles were tested. Additionally, the influence of two commonly used stabilizers (albumin and citrate) on colloid aggregation and the bioactivity of all synthesized materials were examined.

\section{Material and methods}

\section{Synthesis of NP}

The generation of colloidal nanoparticles was achieved by laser ablation of metal foils for silver $(99.99 \%$, Goodfellow $\mathrm{GmbH}$, Germany), gold (99.99 \%, Allgemeine Gold und Silberscheideanstalt AG, Germany), and two silver-gold alloys $\left(\mathrm{Ag}_{4} \mathrm{Au}\right.$ and $\mathrm{AgAu}, 99,99 \%$, accuracy of composition $\pm 1 \mathrm{wt} \%$, fem Research Institute for Precious Metals and Metals Chemistry, Germany) in citrate and BSA solution (SigmaAldrich, Germany). The ablation was carried out in an ablation chamber (volume, $30 \mathrm{ml}$ ) and with a liquid layer of $4 \mathrm{~mm}$ above the target. The laser beam was coupled into the chamber horizontally to minimize interaction with ablation-process-induced bubbles [39]. The detailed description of the ablation setup can be found in [40]. A picosecond laser (Atlantic 532, Ekspla, Lithuania) with 10-ps pulse duration and pulse energy of $110 \mu \mathrm{J}$ at a wavelength of $1,064 \mathrm{~nm}$ was used for the nanoparticle generation. The laser beam was scanned (SCANcube ${ }^{\circledR}$ 10, ScanLab AG, Germany) on the target and focused using an F-Theta lens with focal distance of $100 \mathrm{~mm}$.

The nanoparticles will in the following be referred to as: gold nanoparticles (AuNP), silver nanoparticles (AgNP), alloy nanoparticle with a molar silver-gold ratio of $4: 1\left(\mathrm{Ag}_{4} \mathrm{Au}\right.$, $68.7 \mathrm{wt} \% \mathrm{Ag}$ ) and alloy nanoparticle with a molar silver-gold ratio of 1:1 (AgAu, $35.4 \mathrm{wt} \% \mathrm{Ag})$.

\section{Nanoparticle characterization}

Stock solutions of nanoparticles were stored at $8{ }^{\circ} \mathrm{C}$ after synthesis. Before experimental use they were ultrasonicated for $30 \mathrm{~min}$ at $40 \mathrm{kHz}$ (Elma T710DH, Elma, Germany) and diluted to a NP concentration of $60 \mu \mathrm{g} \mathrm{ml}^{-1}$ with $\mathrm{H}_{2} \mathrm{O}$ bidest. The nanoparticles were dropped on copper grids coated with polyvinyl formal (Formvar) and dried in an exsiccator to prevent humidity-induced reactions of silver on the TEM grid, which has recently been reported to occur [41]. Images were taken with a TEM (Morgagni 268, FEI, The Netherlands). Element analysis of alloy nanoparticles was carried out with high-resolution TEM (FEI Tecnai F20, FEI, The Netherlands).

Dynamic light scattering measurements for evaluation of hydrodynamic size of the colloids were carried out with StabiSizer PMX 200 C (Particle Metrix, Germany), whereas TEM micrographs were used for the determination of the primary particle diameter. The number frequency of size distribution was fitted with OriginPro 8.6G (OriginLab, USA), using a log-normal function, and the polydispersity index was 
calculated according to DIN ISO 13321 as variance $\left(\sigma^{2}\right)$ divided by $\left(X_{c}^{2}\right)$. xA spectrometer (Evolution 201, Thermo Fischer Scientific Inc., USA) covering the spectral range from 190-900 $\mathrm{nm}$ and a glass cuvette with $10 \mathrm{~mm}$ path length and a volume of $4 \mathrm{ml}$ were used for the ultraviolet-visible (UV-vis) measurements. The mass concentration of the nanoparticles was determined in triplicates for different ablation times using a microgram balance (Precisa 40SM-200A, Precisa Gravimetrics AG, Switzerland) with a $10-\mu \mathrm{g}$ accuracy.

NP effects on bacteria

The Gram-positive bacterium Staphylococcus aureus (DSM 20231, DSMZ, Germany) was cultivated in trypticase soy broth (TSB) medium (Oxoid, UK) over night at $37{ }^{\circ} \mathrm{C}$. The next day, $100 \mu$ l of overnight culture was inoculated in $10 \mathrm{ml}$ of fresh TSB medium and cultivated until the exponential growth phase was reached.

Different volumes of ultrasonicated nanoparticles dispersed in $\mathrm{H}_{2} \mathrm{O}$ were mixed with liquid Muller-Hinton agar (CM0405, Oxoid, UK) to achieve NP concentrations of 6$100 \mu \mathrm{g} \mathrm{cm}^{-3}$ within the agar. Each plate was filled with $2 \mathrm{ml}$ agar-nanoparticle mixture, which solidified within $15 \mathrm{~min}$. If NP are fully dissolved and released from the agar nanoparticle composite, the total Ag ion dose would be equivalent to 12 $200 \mu \mathrm{g}$ assuming that the volume of such a suspension is constant. S. aureus was diluted in phosphate-buffered saline to a concentration of $5 \times 10^{3}$ cells ml $^{-1}$. Bacteria suspension $(100 \mu \mathrm{l})$ was plated on agar and incubated overnight at $37^{\circ} \mathrm{C}$. The dosage of $\mathrm{Ag}^{+}$ranged between 24 and $400 \mathrm{ng}^{\text {cell }}{ }^{-1}$ or $1.6 \times 10^{11}$ to $2.7 \times 10^{12}$ silver nanoparticles per bacterial cell in the inoculum. Note that the nanoparticles are immobilized in the agar, so the mass concentration is more relevant than the number concentration. The mass concentration range in the agar gel was selected based on earlier experiences [11]. After $24 \mathrm{~h}$ incubation, colony forming units were counted on four plates. It has recently been reported that duration of storage affects the toxicity of AgNP [42]. In order to eliminate such an influence, the experiments were repeated at four different storage intervals after the synthesis of the NP $(1,4,8$, and 16 weeks).

\section{Cytotoxicity}

Human gingival fibroblasts (HGFib, catalogue number 121 0412, Provitro, Germany) were cultivated and maintained in Dulbecco's modified Eagle's medium (DMEM) (FG0435, Biochrom, Germany) supplemented with $10 \%$ fetal bovine serum (P270521, Pan-Biotech, Germany), $100 \mathrm{U} \mathrm{ml}^{-1}$ penicillin (A2213, Biochrom, Germany), and $100 \mathrm{\mu g} \mathrm{ml}^{-1}$ streptomycin (A2212, Biochrom, Germany) at $37{ }^{\circ} \mathrm{C}$ in $5 \%$ $\mathrm{CO}_{2}$ with $95 \%$ relative humidity. HGFib cells were seeded at a density of $5 \times 10^{3}$ cells per well in 96 -well plates for the 3-(4,5-dimethylthiazol-2-yl)-2,5-diphenyltetrazolium bromide (MTT) assay. After $24 \mathrm{~h}$ of cultivation, the supernatant was removed, and $100 \mu \mathrm{l}$ of fresh media containing different amounts of elemental or alloy NPs was added. Therefore, ultrasonicated nanoparticles were diluted in DMEM to NP concentrations of 6-50 $\mu \mathrm{g} \mathrm{ml}^{-1}$, the total theoretical $\mathrm{Ag}^{+}$ion dose is equivalent to $0.6-5 \mu \mathrm{g}$. The dosage of $\mathrm{Ag}^{+}$ranged between 0.12 and $1 \mathrm{ng}$ cell $^{-1}$, or $8.1 \times 10^{8}$ and $6.75 \times$ $10^{9} \mathrm{NP}$ cell $^{-1}$. Note that the nanoparticles are exposed to the cells in the colloidal state. For each concentration of NPs, four wells were incubated at $37^{\circ} \mathrm{C}$ for $24 \mathrm{~h}$.

The test for mitochondrial function of HGFib cells was performed by a MTT viability assay according to the protocol of the manufacturer (Cell Proliferation Kit 1, Roche Diagnostics, Switzerland ). After $24 \mathrm{~h}$ of incubation, $10 \mu \mathrm{l}$ of staining solution was added to each well. Following $4 \mathrm{~h}$ of incubation, the addition of $100 \mu \mathrm{l}$ of solubilization solution per well caused cell lysis and stain release overnight at $37^{\circ} \mathrm{C}$. The absorbance of the resulting formazan was measured according to the protocol at a wavelength of $540 \mathrm{~nm}$ using a fluorescence microplate reader (Infinite F200, Tecan Group, Germany). Since the surface plasmon resonance (SPR) of Au peaks at $520 \mathrm{~nm}$ with a significant extinction at $540 \mathrm{~nm}$ for increasing amounts of $\mathrm{Au}$ in the AgAu-NP, this referencing background signal is important and has to be performed for each $\mathrm{Ag}$ and Au content separately. To eliminate the influence of nanoparticle extinction as well, wells with corresponding nanoparticle concentration in a medium without cells were measured as reference. Cell viability was classified into different levels of cytotoxicity according to Sjogren et al. [43]: More than $90 \%$ cell viability was interpreted as noncytotoxic, $60-89 \%$ cell viability as slightly cytotoxic, $30-59 \%$ as moderately cytotoxic, and $<30 \%$ as a severely cytotoxic effect.

\section{Statistical analysis}

Differences in cytotoxicity between groups of nanoparticles stabilized with BSA and sodium citrate as well as between all particles stabilized by the same agent were tested by Student's $t$ test. Statistically significant differences were accepted at a $p$ value of 0.05 and below.

\section{Results and discussion}

\section{Characterization of NP}

Laser ablation in liquid provides the production of colloidal nanoparticles from bulk material with a homogeneous composition of elements, in particular if the elements are fully miscible like AgAu, PtIr, or NiFe [32, 33, 39]. This method permits the generation of functionalized colloids without chemical precursors $[44,45]$. Bovine serum albumin, which 


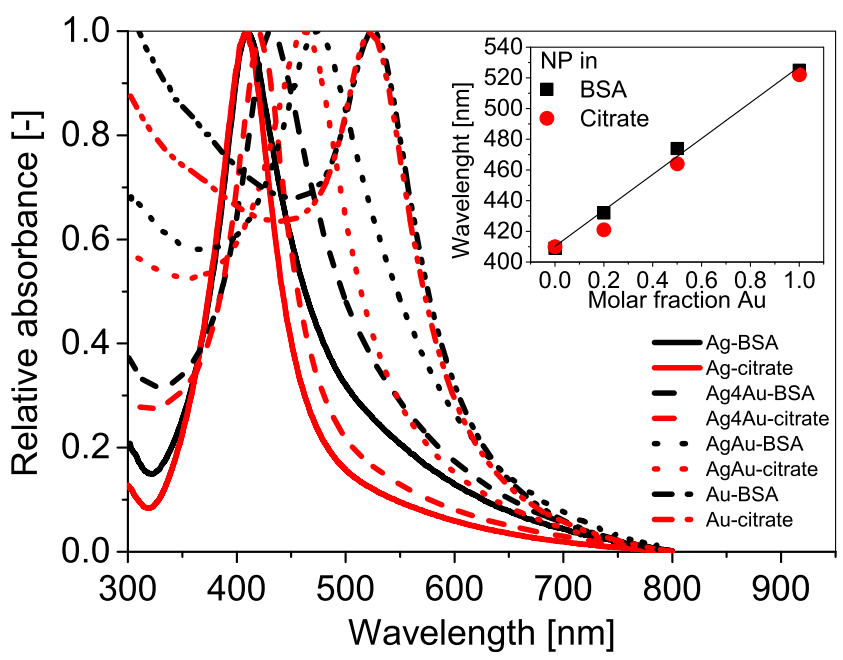

Fig. 1 Validation of alloy composition by plasmon resonance characterization: peak-normalized UV-vis spectra of laser-generated $\mathrm{Ag}, \mathrm{Ag}_{4} \mathrm{Au}$, $\mathrm{AgAu}$, and $\mathrm{Au}$ nanoparticles in aqueous BSA and citrate solutions

adsorbs on the colloid surface, is often used for studies on nanoparticles and their biological effects [46-48] and sodium citrate is widely used in chemical-based synthesis of both gold and silver nanoparticles so that these ligands were applied in comparison.

The UV-vis analysis of laser-generated nanoparticles confirmed the formation of alloys due to the SPR-contribution of each element [49]. The position of SPR peak (Fig. 1) was linearly red-shifted with an increase in the gold molar fraction between the peaks of pure silver and pure gold. The difference in the SPR-peak position between BSA and citrate stabilized nanoparticles resulted from different refractive indices of these molecules. In contrast to the chemically prepared $\mathrm{Ag}-\mathrm{Au}$ nanoparticles, which revealed gradients of element distribution $[50,51]$, the line scan of laser-generated $\mathrm{Ag}-\mathrm{Au}$ nanoparticles showed a uniform distribution of both elements (Fig. 2). The nanoparticle's ultrastructure is specific for the respective synthesis methods. The laser-based one-step method results in the formation of nanoparticles through condensation of ablated material in a cavitation bubble on a microsecond scale $[52,53]$, whereas chemical coprecipitation of $\mathrm{Ag}-\mathrm{Au}$ nanoparticles generally leads to the enrichment of the nobler element $(\mathrm{Au})$ in the nanoparticle core and presenting the less noble element (Ag) at the particle's shell [50]. In Fig. 3, the analysis of TEM micrographs from generated nanoparticles revealed a very similar distribution of primary particle diameter for nanoparticles generated in BSA and citrate solutions (2$4 \mathrm{~nm}$ peak size). Calculated from the peak maximum of the lognormal distribution, the size of all BSA-stabilized nanoparticles ranges between 2.3 and $3.5 \mathrm{~nm}$. In comparison to BSA, citrate-stabilized nanoparticles were slightly bigger, between 4.1 and $4.7 \mathrm{~nm}$. The differences in size distribution for BSA and citrate-stabilized nanoparticles can be attributed to higher affinity of BSA to the nanoparticles, which sterically block the surface, preventing further growth. Particle sizes in studies, which investigated biological effects of silver and gold colloids, often cover size ranges including $1-50 \mathrm{~nm}$ comparable to the presented results $[1,5,13,54,55]$.

Stability of colloids in suspension

Xiu et al. showed that the crucial factor for antibacterial and cytotoxic activity of silver colloids is the particle size and subsequently the release of silver ions. Particle morphology influences the biological activity only by changes in their surface to volume ratio $[56,57]$. The stabilization of nanoparticles within fluids is an important factor for the characterization of these particles in biological systems. Isolated particles have a higher surface to volume ratio than aggregated particles and release more silver ions. Particle aggregation would reduce the ion release.

We compared two different stabilizing agents often used in the synthesis of nanoparticles, bovine serum albumin and sodium citrate. While the aggregation was high for all species of tested nanoparticles when stabilized with sodium citrate, particles were found dispersed when stabilized with BSA and displayed only little aggregation (Fig. 3). Sodium citrate is a
Fig. 2 Ultrastructure of the nanoalloy: TEM-EDX line scan of $\mathrm{AgAu}$ nanoparticles generated by pulsed laser ablation of $\mathrm{AgAu}$ target in liquid. Data indicate homogeneous, non-segregated, non-core-shell ultrastructure
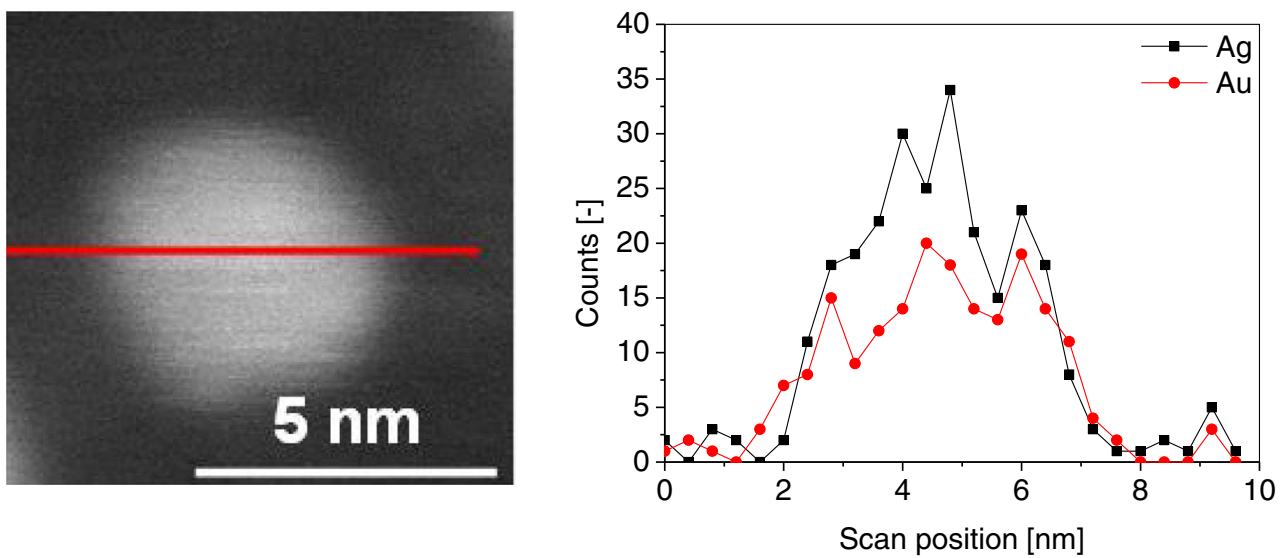

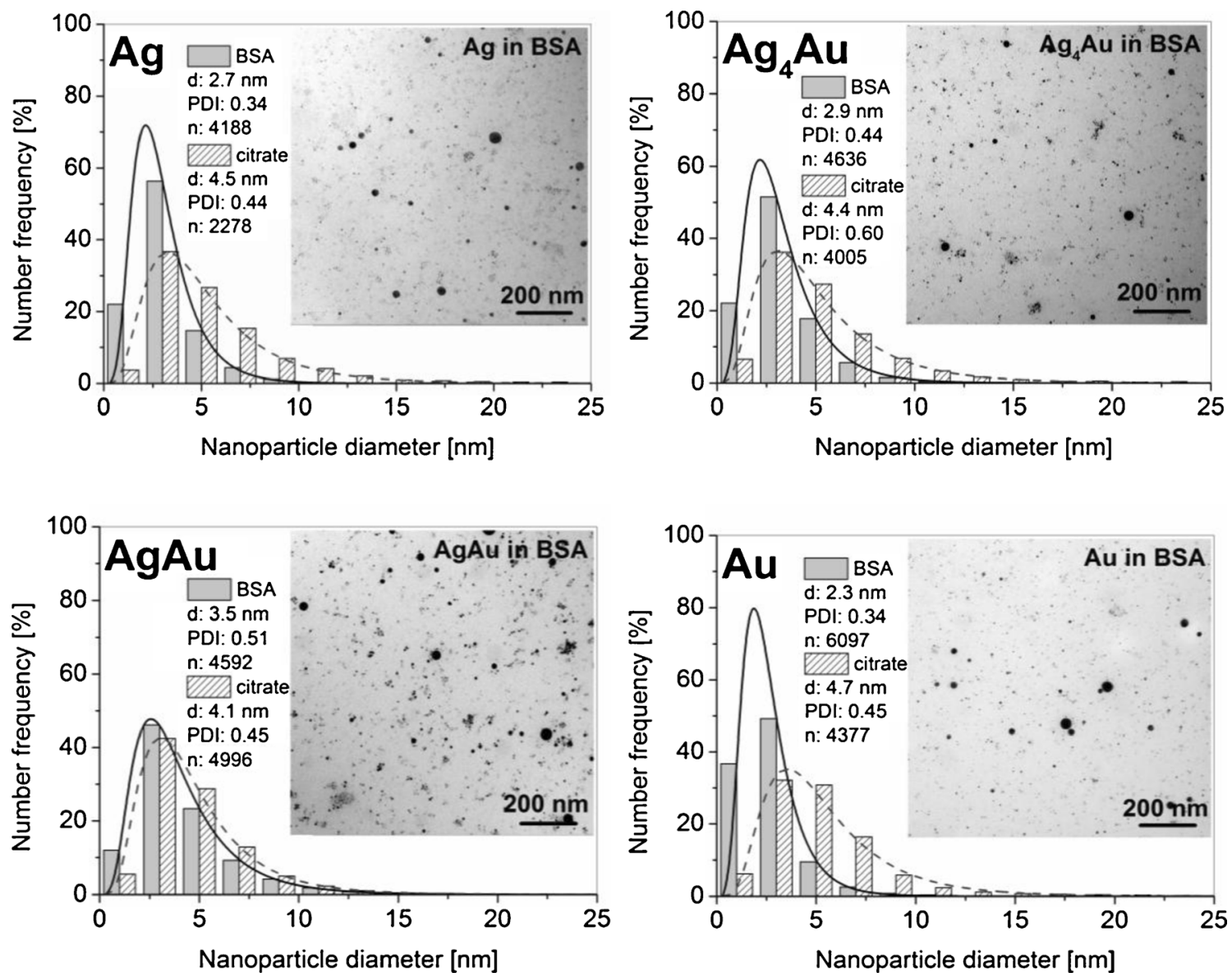

Fig. 3 Nanoparticle diameter histograms and related TEM micrographs of laser-generated $\mathrm{Ag}, \mathrm{Ag}_{4} \mathrm{Au}, \mathrm{AgAu}$, and $\mathrm{Au}$ nanoparticles (BSA samples; for citrate, see Fig. 1 in supporting information, 3d storage

reducing agent and is able to reduce ionic silver to its elemental form. The interaction of released silver ions with citrate molecules, which act as a reductant and stabilizer, is described elsewhere [58]. This induces an equilibrium of dynamic particle growth in the colloid by ripening and dissolution after oxidation due to molecular oxygen present in water. Contrary to steric stabilization with BSA, electrosterically stabilized lasergenerated nanoparticles with citrate molecules aggregate on the TEM grid during the drying process (Fig. 3) (Fig. 1 in supporting information).

Over the course of 16 weeks storage, the amount of aggregation is stable. A final state of aggregation for the nanoparticles was already reached after the first days of storage, when the stabilizing effect was insufficient. This aggregation effect of nanoparticles has been described before and explains the reduced antibacterial and cytotoxic effects of silver nanoparticles and both alloys after storage [42, 59]. Using BSA, storage for several weeks was possible without particle aggregation. We assume that bovine serum albumin was an effective agent for all tested elemental and alloy NP to sterically restrict particle aggregation. Note that BSA is a mass component in serum and many cell culture media anyway.

in $\mathrm{H}_{2} \mathrm{O}$ bidest). Most frequent nanoparticles are in similar size ranges of $2-3 \mathrm{~nm}$ (BSA) and 3-4 $\mathrm{nm}$ (citrate)

Antibacterial activity of nanoparticles

Biological effects of AgAu alloy nanoparticles have only been tested in a few studies, especially since aqueous synthesis of particles with a homogeneous distribution of gold and silver atoms is difficult to achieve. Previous studies have often been conducted with coated particles synthesized in a coprecipitation method, resulting in a gold core and a silver shell. Recently, particles with a core-shell composition with a higher gold fraction at the particle core and a higher silver fraction on the particle surface were produced by chemical synthesis and analyzed for their biological effects [50, 59].

It could be expected that the release of Ag ions decreases proportionally to the increasing gold molar fraction, due to the change of electrochemical potential [60]. However, disproportional anomalies may take effect on the nanoscale: recently, Alissawi et al. showed that different compositions of $\mathrm{AgAu}$ nanoparticles led to different kinetics of ion release and were not proportional to the amount of silver in each composition. This effect was explained by entropy of mixing of $\mathrm{AgAu}$ alloys. The immersion of AgAu alloy has shown the highest ion release after $40 \mathrm{~min}$ with decreasing release rates after $2 \mathrm{~h}$, 
Table 1 Minimal inhibitory concentration (MIC) against S. aureus and moderately cytotoxic concentration (Tox50) against HGFib of NP with different $\mathrm{Ag} / \mathrm{Au}$ ratios and stabilizing agents (sodium citrate and BSA)

\begin{tabular}{|c|c|c|c|c|}
\hline \multirow[b]{2}{*}{$\begin{array}{l}\text { Colloid and stabilizing } \\
\text { agent }\end{array}$} & \multicolumn{2}{|l|}{ NP mass dose } & \multicolumn{2}{|c|}{ Ag mass in NP dose } \\
\hline & $\begin{array}{l}\text { MIC } \\
\left.(\mu \mathrm{g} \mathrm{NP} \mathrm{cm})^{-3}\right)\end{array}$ & 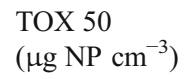 & $\begin{array}{l}\text { MIC } \\
\left(\mu \mathrm{g} \mathrm{Ag} \mathrm{cm}^{-3}\right)\end{array}$ & $\begin{array}{l}\text { TOX } 50 \\
\left(\mu \mathrm{Ag} \mathrm{cm}^{-3}\right)\end{array}$ \\
\hline $\mathrm{Ag}+\mathrm{BSA}$ & 12 & 9 & 12 & 9 \\
\hline $\mathrm{Ag}+\mathrm{Na}$ citrate & 25 & 29 & 25 & 29 \\
\hline $\mathrm{Ag}_{4} \mathrm{Au}+\mathrm{BSA}$ & 25 & 9 & 17.2 & 6.2 \\
\hline $\mathrm{Ag}_{4} \mathrm{Au}+\mathrm{Na}$ citrate & 50 & 55 & 34.4 & 37.8 \\
\hline $\mathrm{AgAu}+\mathrm{BSA}$ & 100 & 25 & 35.4 & 8.9 \\
\hline $\mathrm{AgAu}+\mathrm{Na}$ citrate & $>100$ & $>100$ & $>35.4$ & $>35.4$ \\
\hline $\mathrm{Au}+\mathrm{BSA}$ & $>100$ & $>50$ & NA & $\mathrm{NA}$ \\
\hline $\mathrm{Au}+\mathrm{Na}$ citrate & $>100$ & $>100$ & NA & NA \\
\hline
\end{tabular}

$1 \mathrm{~d}$ and $2 \mathrm{~d}$. After 1 day of exposure, the ion release changes and increases relative to the silver amount in the alloy. According to these results, the ion release of AgAu nanoparticles could be adjusted to further applications just by variation of the gold molar ratio and nanoparticle sizes [61].

With an increasing ratio of silver, the antibacterial effect of laser-generated nanoparticles on $S$. aureus increased. With the exception of gold and aggregated AgAu (stabilized by sodium citrate), all NP inhibited bacterial growth within the used concentration range from 6 to $100 \mathrm{\mu g} \mathrm{ml}^{-1}$ (Table 1).

Nanoparticles synthesized from pure silver had the strongest antibacterial effect with a complete growth inhibition beginning at a concentration of $12 \mu \mathrm{g} \mathrm{ml}^{-1}$. The antibacterial effect of silver nanoparticles on $S$. aureus was comparable to other studies examining the biological effects of silver colloids $[5,10,17]$. Taking similar particle sizes into account, a comparable antibacterial effect between laser-generated and chemically synthesized AgNP can be assumed.

Elemental gold nanoparticles synthesized with the described method showed no antibacterial effect within the used concentration range of $6-100 \mu \mathrm{g} \mathrm{cm}{ }^{-3}$. Interestingly, the antibacterial effect of gold-alloyed AgNP on $S$. aureus decreased much more when the silver ratio within the alloys is taken in consideration.

By decreasing the molar silver fraction in the nanoalloy from $100 \%(\mathrm{AgNP})$ to $80 \%\left(\mathrm{Ag}_{4} \mathrm{Au}\right)$, the minimal inhibitory concentration (MIC), and therefore the effective concentration of nanoparticles needed to inhibit growth, was increased by $100 \%$ (Table 1). This was observed for both alloys whether stabilized with BSA or sodium citrate. For the AgAu alloy with a $50 \%$ molar silver fraction (equal to $35.4 \%$ of silver mass fraction), the total mass dose of silver was one third of

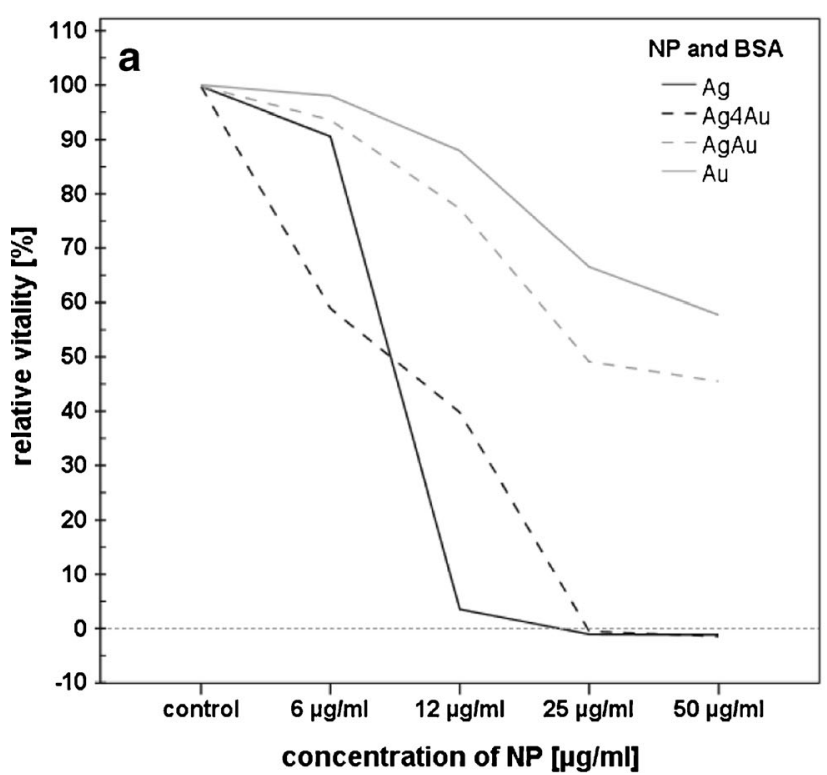

Fig. 4 Influence of nanoparticle composition and mass dose on toxicity: cell viability of human gingival fibroblasts after a treatment with four different elemental and alloy nanoparticles ( $\mathrm{Ag}, \mathrm{Ag}_{4} \mathrm{Au}, \mathrm{AgAu}$, and $\left.\mathrm{Au}\right)$

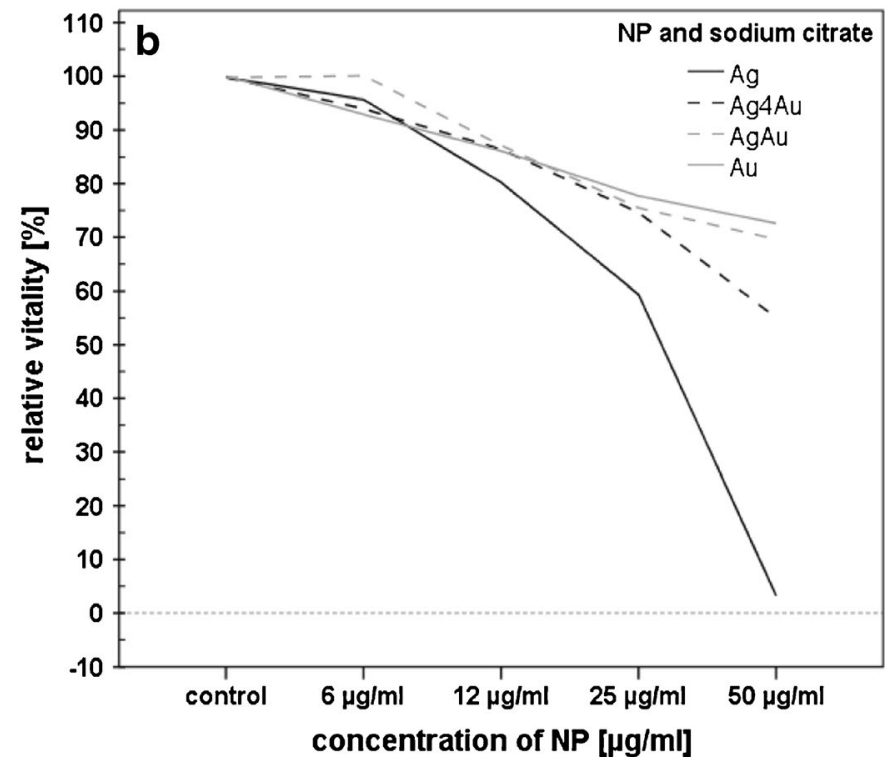

stabilized with a bovine serum albumin and $\mathbf{b}$ sodium citrate, $50 \%$ relative vitality and lower is set as a threshold for moderate and severe cytotoxicity 

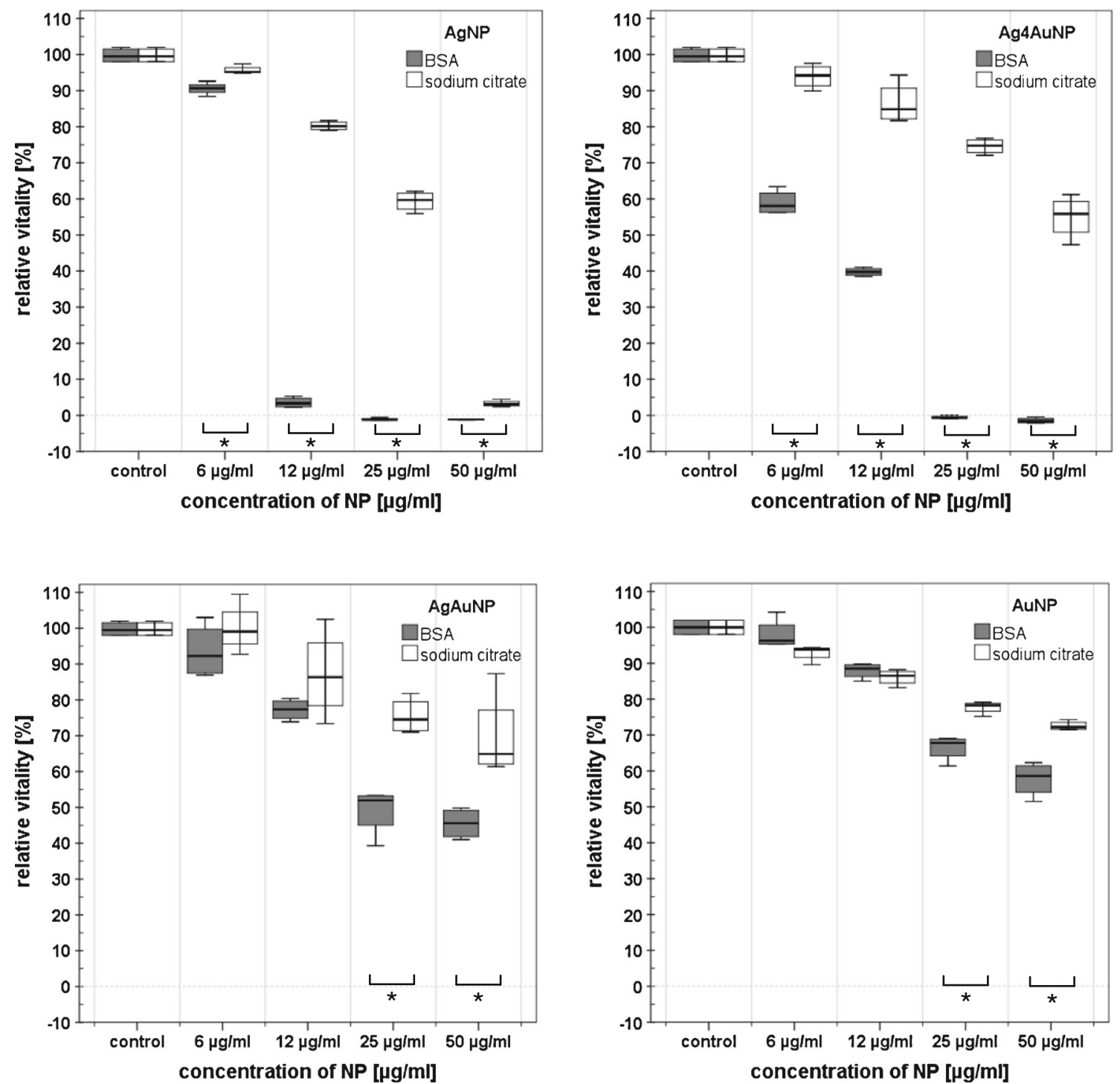

Fig. 5 Cell viability of human gingival fibroblasts after the treatment with four different elemental and alloy colloids $\left(\mathrm{Ag}, \mathrm{Au}, \mathrm{AgAu}, \mathrm{and} \mathrm{Ag} \mathrm{Au}_{4} \mathrm{Au}\right.$ stabilized with bovine serum albumin and sodium citrate (statistically significant differences between both groups of stabilizers, $p<0.05$ )

the pure silver particles, but the MIC was eight times higher than for the particles stabilized by BSA. This reduction of the antibacterial effect was unexpected considering the total silver dose. Physicochemical properties of gold and silver could be the reason for this effect. Beside the kinetic effect, which was described by Alissawi et al. [37], a second effect that may influence silver ion release could be discussed. Since BSA chemisorption to gold surfaces via cysteine or disulfide moieties is more pronounced with an increase of the gold fraction, the protein corona will be more distinct [23, 24]. This effect may sterically hinder the ion release. Differences between bovine serum albumin and sodium citrate regarding their function as stabilizers of antibacterial effects were distinct. Nanoparticles stabilized by sodium citrate had to be used in a twofold concentration to achieve the same reduction in bacterial growth compared to NP stabilized by BSA. In consideration of the differences in aggregation state between nanoparticles stabilized with BSA and sodium citrate, the lower effect of bacterial growth reduction can be attributed to reduction properties of citrate, which provoke reduction of bio active silver ions to elemental silver [50]. Furthermore, primary particles in suspension feature a higher surface/volume ratio than aggregated colloids and release more silver ions at the same silver concentration [62]. After a storage time of 16 weeks and repetition of the cell culture experiments, most particles showed the same threshold concentration at which the bacterial growth was inhibited completely (Fig. 2, Table 2 in Supplementary info).

In summary, BSA stabilized and preserved the antibacterial effect of pure Ag and both nanoalloys more efficiently compared to sodium citrate. Alloying silver with gold caused biological deactivation of a disproportionally high silver fraction in alloy nanoparticles. 

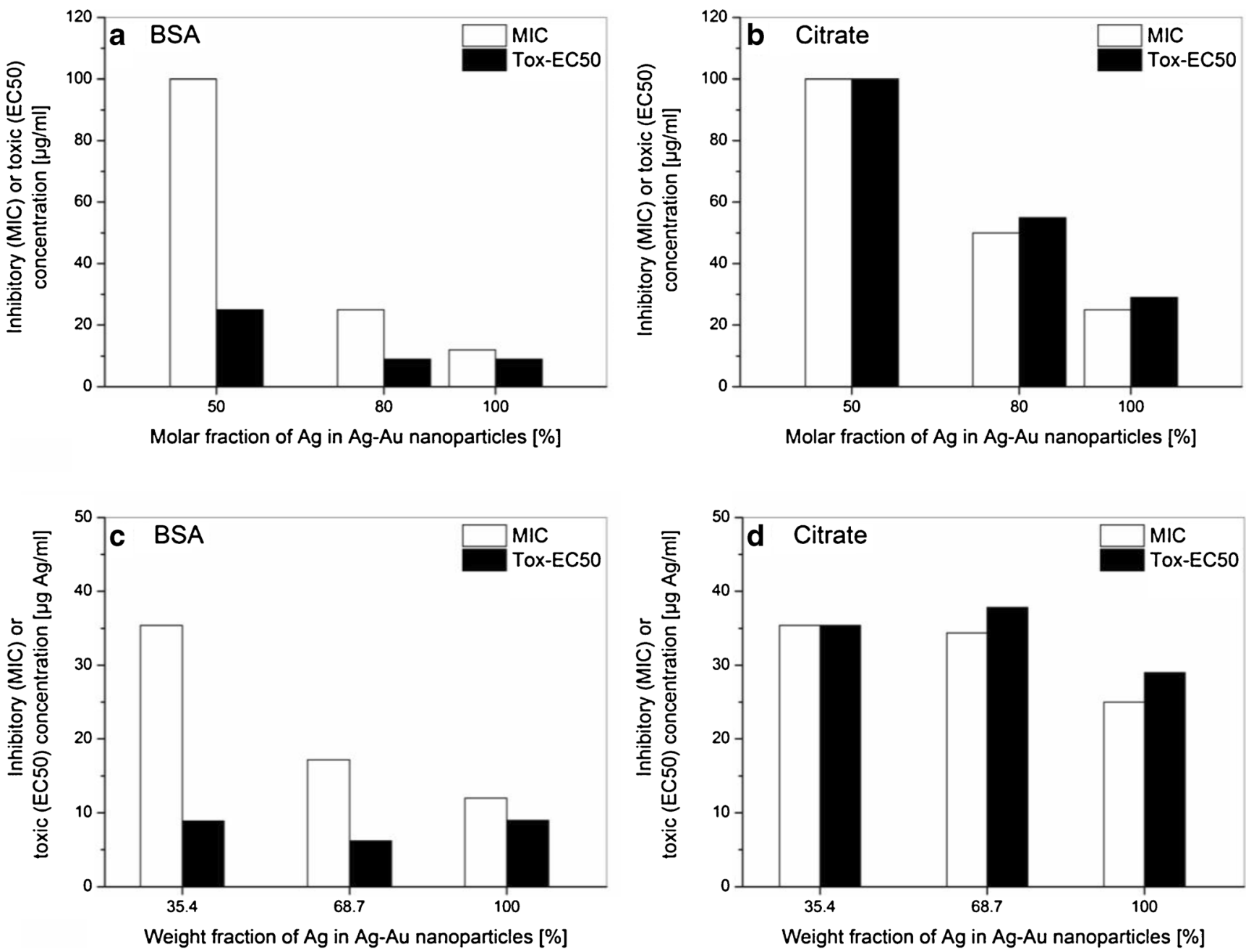

Fig. 6 Silver dosage dependent cell viability of human gingival fibroblasts a, b and antibacterial activity on $S$. aureus $\mathbf{c}, \mathbf{d}$ after treatment with three different nanocolloids ( $\mathrm{Ag}, \mathrm{AgAu}, \mathrm{Ag} 4 \mathrm{Au}$ ) stabilized with $\mathbf{a}, \mathbf{c}$ bovine serum albumin and $\mathbf{b}, \mathbf{d}$ sodium citrate

\section{Cytotoxicity of NP}

Cytotoxicity of silver nanoparticles was described in many studies, but the mechanisms of particle-cell interactions negatively affecting cell viability are manifold and complex [16]. Differences in particle size, charge, and cell type can show very variable results [63]. It was described in former studies that laser-generated silver NPs had strong cytotoxic effects on HGFib comparable with nanoparticles synthesized by other methods [10]. Severe cytotoxicity was reached at the same concentration of nanoparticles as reported widely in literature [1].

In the present study, cytotoxicity was measured with an MTT assay, which depicts the metabolic activity of the HGFib. Comparing BSA and sodium citrate, statistically significant differences regarding their influence on cytotoxicity of nanoparticles were found. In accordance with the result for antibacterial activity, particles stabilized by BSA showed a stronger effect on cell metabolic activity particles stabilized by the reducing agent sodium citrate. Nanoparticles combined with BSA kept their cytotoxic effect, but colloids with sodium citrate showed a statistically significant reduction of cytotoxicity.

After 1 week storage, silver nanoparticles stabilized with BSA showed - deriving from a reduced metabolic activity - a slightly cytotoxic effect at a concentration of $6 \mu \mathrm{g} \mathrm{ml}^{-1}$ and severe cytotoxicity at $12 \mathrm{\mu g} \mathrm{ml}^{-1}$. This steep decrease in cell survival ended at $25 \mu \mathrm{g} \mathrm{ml}^{-1}$ where all metabolic activity of HGFib was completely stopped. After 16 weeks of particle storage, the AgNP showed a decreased effect on cell survival with now only moderate cytotoxicity at $12 \mu \mathrm{g} \mathrm{ml}^{-1}$. But even here, death of all cells was observed at $25 \mu \mathrm{g} \mathrm{ml}^{-1}$ (data for 4, 8 , and 16 weeks shown in Fig. $3 \mathrm{a}-\mathrm{h}$ in supplementary data).

Silver nanoparticles stabilized with sodium citrate showed a cytotoxic effect only at higher concentrations of nanoparticles (Fig. 4). They showed also a slightly cytotoxic effect on HGFib at concentrations of 6 to $25 \mathrm{\mu g} \mathrm{ml}^{-1}$. At a NP concentration of $50 \mu \mathrm{g} \mathrm{ml}^{-1}$, a severe effect on cell viability was 
measured. After longer storage, no complete cell death was observable even at $50 \mu \mathrm{g} \mathrm{ml}^{-1}$. Again, differences in cytotoxic effects between nanoparticles stabilized with BSA and sodium citrate can be explained in accordance with the statement for antibacterial activity.

Elemental gold NP showed a moderate cytotoxicity at concentration of $25 \mu \mathrm{g} \mathrm{ml}^{-1}$ and higher, which is reported by other authors. They described the ability of AuNP to enter the cell nucleus of cells and subsequently interacting with proteins and enzymes within cells [16, 64].

The reduction of silver-related effects by alloying $\mathrm{Ag}$ with $\mathrm{Au}$ on the nanoscale was also observed for cytotoxicity. With an increasing fraction of gold within the nanoparticles the cytotoxic effect was reduced more strongly than expected if the silver mass dose would be taken into account as the bioactive component (Figs. 5 and 6).

$\mathrm{Ag}_{4} \mathrm{Au}$ stabilized with BSA showed also a decrease in cell viability with higher concentrations of nanoparticles, but the decrease was less severe than for pure AgNP. Strong cytotoxicity was first observed at a NP concentration of $25 \mu \mathrm{g} \mathrm{ml}{ }^{-1}$, after 16 weeks of storage there cytotoxicity was reduced. Nanoparticles stabilized by sodium citrate showed only a small decrease in cell vitality even at higher concentrations of NP. At $50 \mu \mathrm{g} \mathrm{ml}^{-1}$, there was only a moderate cytotoxicity.

The cytotoxic effect of the alloy $\mathrm{AgAu}$ was similar to $\mathrm{Ag}_{4} \mathrm{Au}$. A severe reduction of cell survival would have been expected at a concentration of $34 \mu \mathrm{g} \mathrm{ml}^{-1}$ of $\mathrm{AgAu}$, which would contain the same silver mass as pure silver NP at a concentration of $12 \mu \mathrm{g} \mathrm{ml}^{-1}$. Interestingly, even at $50 \mu \mathrm{g} \mathrm{ml}^{-1}$, the nanoparticles had only a moderately cytotoxic effect on HGFib. Especially AgAu particles stabilized by sodium citrate showed a similar curve compared to $\mathrm{Ag}_{4} \mathrm{Au}$. Overall, bioactivity of $\mathrm{Ag}$ nanoparticles is significantly decreased by alloying with Au. A given mass dose of $\mathrm{Ag}$ is more effective if presented as elemental Ag compared to an Ag equivalent higher mass dose of AgAu alloy nanoparticles (Figs. 5 and 6). Hence, the electrochemical series and redox potential of $\mathrm{Ag}$ and $\mathrm{Au}$ is not expected to be the only influencing factor.

These effects were also described by other studies, which used chemically prepared gold-silver alloy nanoparticles [59]. However, both studies used alloy colloids with a core to shell increase in the silver ratio and explained the reduced cytotoxic effects with this heterogenic ultrastructure of the particles. In our case, homogeneous ultrastructure has been observed for $\mathrm{Ag}-\mathrm{Au}$ alloy fabricated by laser ablation in liquid [65] and has also been reported into detail for other metal alloy nanoparticles fabricated by laser ablation [34]. In consequence, heterogeneity cannot be taken as explanation. Based on findings from the literature, we speculate that entropy of mixing [37] and effect of protein corona affected the silver ion release $[23,24]$.

\section{Conclusion}

Silver-gold alloy nanoparticles with a homogeneous ultrastructure and comparable size were analyzed for their biological activity and compared to elemental Ag und Au nanoparticles. Both antibacterial and cytotoxic effects decreased disproportionately with increasing fraction of gold indicating a physicochemical interaction between both elements. It is evident that gold has a deactivating effect on silver ion release even if no core-shell distribution, but homogeneous of both elements in the nanoparticle ultrastructure is present [65]. It could also be confirmed that citrate is much more potent in deactivating silver than BSA [17]. Beside this, no influence of storing laser-generated, BSA- and citrate-stabilized nanoparticle colloids over 16 weeks could be observed in comparison to the freshly prepared colloids. The precise setting of the gold-silver ratio and the homogeneous distribution of both elements within nanoparticles by laser ablation in liquid opens new chances to control the silver ion release and the biological effect by alloying on the nanoscale.

Acknowledgments We thank the German Research Foundation (DFG) for funding the priority program 1313 as well as Jan Hegermann, Manuela Kellner, and Mark Kühnel (Institute for Functional and Applied Anatomy, Medical School Hannover) for their assistance with the TEMimaging. We would also like to thank Dennis Buchbach for his assistance in the generation of the nanoparticle colloids.

Conflicts of interest None.

Open Access This article is distributed under the terms of the Creative Commons Attribution License which permits any use, distribution, and reproduction in any medium, provided the original author(s) and the source are credited.

\section{References}

1. Chernousova S, Epple M (2013) Silver as antibacterial agent: ion, nanoparticle, and metal. Angew Chem Int Ed Engl 52(6):1636-1653. doi:10.1002/anie.201205923

2. Daniel MC, Astruc D (2004) Gold nanoparticles: assembly, supramolecular chemistry, quantum-size-related properties, and applications toward biology, catalysis, and nanotechnology. Chem Rev 104(1):293-346

3. Saha K, Agasti SS, Kim C, Li XN, Rotello VM (2012) Gold nanoparticles in chemical and biological sensing. Chem Rev 112(5): 2739-2779

4. Chen X, Schluesener HJ (2008) Nanosilver: a nanoproduct in medical application. Toxicol Lett 176(1):1-12

5. Kim JS, Kuk E, Yu KN, Kim JH, Park SJ, Lee HJ, Kim SH, Park YK, Park YH, Hwang CY, Kim YK, Lee YS, Jeong DH, Cho MH (2007) Antimicrobial effects of silver nanoparticles. Nanomedicine 3(1):95-101

6. Feng QL, Wu J, Chen GQ, Cui FZ, Kim TN, Kim JO (2000) A mechanistic study of the antibacterial effect of silver ions on Escherichia coli and Staphylococcus aureus. J Biomed Mater Res 52(4):662-668

7. Morones JR, Elechiguerra JL, Camacho A, Holt K, Kouri JB, Ramirez JT, Yacaman MJ (2005) The bactericidal effect of silver 
nanoparticles. Nanotechnology 16(10):2346-2353. doi:10.1088/ 0957-4484/16/10/059

8. Lu Y, Spyra P, Mei Y, Ballauff M, Pich A (2007) Composite hydrogels: robust carriers for catalytic nanoparticles. Macromol Chem Physic 208(3):254-261

9. Thomas V, Yallapu MM, Sreedhar B, Bajpai SK (2007) A versatile strategy to fabricate hydrogel-silver nanocomposites and investigation of their antimicrobial activity. J Colloid Interface Sci 315(1): 389-395. doi:10.1016/j.jcis.2007.06.068

10. Ghosh S, Kaushik R, Nagalakshmi K, Hoti SL, Menezes GA, Harish BN, Vasan HN (2010) Antimicrobial activity of highly stable silver nanoparticles embedded in agar-agar matrix as a thin film. Carbohydr Res 345(15):2220-2227. doi:10.1016/j.carres.2010.08.001

11. Grade S, Eberhard J, Wagener P, Winkel A, Sajti CS, Barcikowski S, Stiesch M (2012) Therapeutic window of ligand-free silver nanoparticles in agar-embedded and colloidal state: in vitro bactericidal effects and cytotoxicity. Adv Eng Mater 14(5):231. doi:10.1002/ adem. 201180016

12. Martinez-Gutierrez F, Olive PL, Banuelos A, Orrantia E, Nino N, Sanchez EM, Ruiz F, Bach H, Av-Gay Y (2010) Synthesis, characterization, and evaluation of antimicrobial and cytotoxic effect of silver and titanium nanoparticles. Nanomedicine 6(5):681-688. doi: 10.1016/j.nano.2010.02.001

13. Asharani PV, Hande MP, Valiyaveettil S (2009) Anti-proliferative activity of silver nanoparticles. BMC Cell Biol 10:65. doi:10.1186/ 1471-2121-10-65

14. Braydich-Stolle L, Hussain S, Schlager JJ, Hofmann MC (2005) In vitro cytotoxicity of nanoparticles in mammalian germline stem cells. Toxicol Sci 88(2):412-419

15. Hussain SM, Hess KL, Gearhart JM, Geiss KT, Schlager JJ (2005) In vitro toxicity of nanoparticles in BRL 3A rat liver cells. Toxicol in Vitro 19(7):975-983. doi:10.1016/j.tiv.2005.06.034

16. Johnston HJ, Hutchison G, Christensen FM, Peters S, Hankin S, Stone V (2010) A review of the in vivo and in vitro toxicity of silver and gold particulates: particle attributes and biological mechanisms responsible for the observed toxicity. Crit Rev Toxicol 40(4):328346. doi:10.3109/10408440903453074

17. Grade S, Eberhard J, Neumeister A, Wagener P, Winkel A, Stiesch M, Barcikowski S (2012) Serum albumin reduces the antibacterial and cytotoxic effects of hydrogel-embedded colloidal silver nanoparticles. Rsc Adv 2(18):7190-7196

18. Rath D, Barcikowski S, de Graaf S, Garrels W, Grossfeld R, Klein S, Knabe W, Knorr C, Kues W, Meyer H, Michl J, Moench-Tegeder G, Rehbock C, Taylor U, Washausen S (2013) Sex selection of sperm in farm animals: status report and developmental prospects. Reproduction 145(1):R15-R30. doi:10.1530/REP-12-0151

19. Taylor U, Barchanski A, Garrels W, Klein S, Kues W, Barcikowski S, Rath D (2012) Toxicity of gold nanoparticles on somatic and reproductive cells. Adv Exp Med Biol 733:125-133. doi:10.1007/978-94007-2555-3 12

20. Brewer SH, Glomm WR, Johnson MC, Knag MK, Franzen S (2005) Probing BSA binding to citrate-coated gold nanoparticles and surfaces. Langmuir 21(20):9303-9307. doi:10.1021/ la050588t

21. Wangoo N, Suri CR, Shekhawat G (2008) Interaction of gold nanoparticles with protein: a spectroscopic study to monitor protein conformational changes. Appl Phys Lett 92 (13): 133104

22. Rehbock C, Merk V, Gamrad L, Streubel R, Barcikowski S (2013) Size control of laser-fabricated surfactant-free gold nanoparticles with highly diluted electrolytes and their subsequent bioconjugation. Phys Chem Chem Phys 15(9):3057-3067

23. Cedervall T, Lynch I, Lindman S, Berggard T, Thulin E, Nilsson H, Dawson KA, Linse S (2007) Understanding the nanoparticleprotein corona using methods to quantify exchange rates and affinities of proteins for nanoparticles. Proc Natl Acad Sci U S A 104(7):2050-2055
24. Walczyk D, Bombelli FB, Monopoli MP, Lynch I, Dawson KA (2010) What the cell "sees" in bionanoscience. J Am Chem Soc 132(16):5761-5768

25. Liu JH, Wang AQ, Chi YS, Lin HP, Mou CY (2005) Synergistic effect in an $\mathrm{Au}-\mathrm{Ag}$ alloy nanocatalyst: $\mathrm{CO}$ oxidation. J Phys Chem B 109(1):40-43

26. Zeng HB, Du XW, Singh SC, Kulinich SA, Yang SK, He JP, Cai WP (2012) Nanomaterials via laser ablation/irradiation in liquid: a review. Adv Funct Mater 22(7):1333-1353

27. Amendola V, Meneghetti M (2013) What controls the composition and the structure of nanomaterials generated by laser ablation in liquid solution? Phys Chem Chem Phys 15(9):3027-3046

28. Petersen S, Barcikowski S (2009) Conjugation efficiency of laserbased bioconjugation of gold nanoparticles with nucleic acids. J Phys Chem C 113:19830-19835

29. Barchanski A, Hashimoto N, Petersen S, Sajti CL, Barcikowski S (2012) Impact of spacer and strand length on oligonucleotide conjugation to the surface of ligand-free laser-generated gold nanoparticles. Bioconjug Chem 23(5):908-915

30. Wagener P, Schwenke A, Barcikowski S (2012) How citrate ligands affect nanoparticle adsorption to microparticle supports. Langmuir 28(14):6132-6140

31. Lopez-Sanchez JA, Dimitratos N, Hammond C, Brett GL, Kesavan L, White S, Miedziak P, Tiruvalam R, Jenkins RL, Carley AF, Knight D, Kiely CJ, Hutchings GJ (2011) Facile removal of stabilizer-ligands from supported gold nanoparticles. Nat Chem 3(7):551-556

32. Jakobi J, Menendez-Manjon A, Chakravadhanula VS, Kienle L, Wagener P, Barcikowski S (2011) Stoichiometry of alloy nanoparticles from laser ablation of PtIr in acetone and their electrophoretic deposition on PtIr electrodes. Nanotechnology 22(14):145601. doi: 10.1088/0957-4484/22/14/145601

33. Jakobi J, Petersen S, Menendez-Manjon A, Wagener P, Barcikowski S (2010) Magnetic alloy nanoparticles from laser ablation in cyclopentanone and their embedding into a photoresist. Langmuir 26(10):6892-6897

34. Zhang JM, Oko DN, Garbarino S, Imbeault R, Chaker M, Tavares AC, Guay D, Ma DL (2012) Preparation of PtAu alloy colloids by laser ablation in solution and their characterization. J Phys Chem C 116(24):13413-13420

35. Lee I, Han SW, Kim K (2001) Production of Au-Ag alloy nanoparticles by laser ablation of bulk alloys. Chem Commun (Camb) 18 : 1782-1783

36. Menendez-Manjon A, Schwenke A, Steinke T, Meyer M, Giese U, Wagener P, Barcikowski S (2013) Ligand-free gold-silver nanoparticle alloy polymer composites generated by picosecond laser ablation in liquid monomer. Appl Phys a-Mater 110(2):343-350

37. Alissawi N, Zaporojtchenko V, Strunskus T, Kocabas I, Chakravadhanula VSK, Kienle L, Garbe-Schonberg D, Faupel F (2013) Effect of gold alloying on stability of silver nanoparticles and control of silver ion release from vapor-deposited $\mathrm{Ag}-\mathrm{Au} /$ polytetrafluoroethylene nanocomposites. Gold Bull 46(1):3-11

38. Hahn A, Fuhlrott J, Loos A, Barcikowski S (2012) Cytotoxicity and ion release of alloy nanoparticles. J Nanopart Res 14 (1)

39. Menendez-Manjon A, Jakobi J, Schwabe K, Krauss J, Barcikowski S (2009) Mobility of nanoparticles generated by femtosecond laser ablation in liquids and its application to surface patterning. J Laser Micro / Nanoengineering 4(2):95-99

40. Nachev P, van 'T Zand DD, Coger V, Wagener P, Reimers K, Vogt PM, Barcikowski S, Pich A (2012) Synthesis of hybrid microgels by coupling of laser ablation and polymerization in aqueous medium. $\mathrm{J}$ Laser Appl 24 (4):042012

41. Glover RD, Miller JM, Hutchison JE (2011) Generation of metal nanoparticles from silver and copper objects: nanoparticle dynamics on surfaces and potential sources of nanoparticles in the environment. ACS Nano 5(11):8950-8957 
42. Kittler S, Greulich C, Diendorf J, Köller M, Epple M (2010) Toxicity of silver nanoparticles increases during storage because of slow dissolution under release of silver ion. Chem Mater 22: $4548-4554$

43. Sjogren G, Sletten G, Dahl JE (2000) Cytotoxicity of dental alloys, metals, and ceramics assessed by millipore filter, agar overlay, and MTT tests. J Prosthet Dent 84(2):229-236. doi:10.1067/mpr.2000. 107227

44. Barsch N, Jakobi J, Weiler S, Barcikowski S (2009) Pure colloidal metal and ceramic nanoparticles from high-power picosecond laser ablation in water and acetone. Nanotechnology 20(44):445603

45. Petersen S, Barcikowski S (2009) In situ bioconjugation: Single-step approach to tailored nanoparticle-bioconjugates by ultrashort pulsed laser ablation. Adv Funct Mater 19:1-6

46. Garza-Ocanas L, Ferrer DA, Burt J, Diaz-Torres LA, Ramirez Cabrera M, Rodriguez VT, Lujan Rangel R, Romanovicz D, JoseYacaman M (2010) Biodistribution and long-term fate of silver nanoparticles functionalized with bovine serum albumin in rats. Metallomics 2(3):204-210. doi:10.1039/b916107d

47. Ravindran A, Singh A, Raichur AM, Chandrasekaran N, Mukherjee A (2010) Studies on interaction of colloidal Ag nanoparticles with bovine serum albumin (BSA). Colloids Surf B Biointerfaces 76(1):32-37. doi:10.1016/j.colsurfb.2009.10.005

48. Tsai DH, DelRio FW, Keene AM, Tyner KM, MacCuspie RI, Cho TJ, Zachariah MR, Hackley VA (2011) Adsorption and conformation of serum albumin protein on gold nanoparticles investigated using dimensional measurements and in situ spectroscopic methods. Langmuir 27(6):2464-2477

49. Besner S, Meunier M (2010) Femtosecond laser synthesis of AuAg nanoalloys: photoinduced oxidation and ions release. J Phys Chem C 114(23):10403-10409

50. Mahl D, Diendorf J, Ristig S, Greulich C, Li ZA, Farle M, Koller M, Epple M (2012) Silver, gold, and alloyed silver-gold nanoparticles: characterization and comparative cell-biologic action. J Nanopart Res 14(10): $1-10$

51. Boote B, Byun H, Kim J-H (2013) One-pot synthesis of various Ag$\mathrm{Au}$ bimetallic nanoparticles with tunable absorption properties at room temperature. Gold Bull 46(3):185-193. doi:10.1007/s13404013-0099-4

52. Wagener P, Ibrahimkutty S, Menzel A, Plech A, Barcikowski S (2013) Dynamics of silver nanoparticle formation and agglomeration inside the cavitation bubble after pulsed laser ablation in liquid. Phys Chem Chem Phys 15(9):3068-3074

53. Ibrahimkutty S, Wagener P, Menzel A, Plech A, Barcikowski S (2012) Nanoparticle formation in a cavitation bubble after pulsed laser ablation in liquid studied with high time resolution small angle X-ray scattering. Appl Phys Lett 101 (10):103104

54. Lewinski N, Colvin V, Drezek R (2008) Cytotoxicity of nanoparticles. Small 4(1):26-49. doi:10.1002/smll.200700595

55. Murawala P, Phadnis SM, Bhonde RR, Prasad BL (2009) In situ synthesis of water dispersible bovine serum albumin capped gold and silver nanoparticles and their cytocompatibility studies. Colloids Surf B Biointerfaces 73(2):224-228. doi:10.1016/j.colsurfb.2009.05.029

56. Xiu ZM, Zhang QB, Puppala HL, Colvin VL, Alvarez PJJ (2012) Negligible particle-specific antibacterial activity of silver nanoparticles. Nano Lett 12(8):4271-4275

57. Sotiriou GA, Pratsinis SE (2010) Antibacterial activity of nanosilver ions and particles. Environ Sci Technol 44(14):5649-5654

58. Pillai ZS, Kamat PV (2004) What factors control the size and shape of silver nanoparticles in the citrate ion reduction method? J Phys Chem B 108(3):945-951

59. Li T, Albee B, Alemayehu M, Diaz R, Ingham L, Kamal S, Rodriguez M, Bishnoi SW (2010) Comparative toxicity study of $\mathrm{Ag}, \mathrm{Au}$, and $\mathrm{Ag}-\mathrm{Au}$ bimetallic nanoparticles on Daphnia magna. Anal Bioanal Chem 398(2):689-700. doi:10.1007/s00216-0103915-1

60. Hahn A, Gunther S, Wagener P, Barcikowski S (2011) Electrochemistrycontrolled metal ion release from silicone elastomer nanocomposites through combination of different metal nanoparticles. J Mater Chem 21(28): 10287-10289

61. Alissawi N, Zaporojtchenko V, Strunskus T, Hrkac T, Kocabas I, Erkartal B, Chakravadhanula VSK, Kienle L, Grundmeier G, GarbeSchonberg D, Faupel F (2012) Tuning of the ion release properties of silver nanoparticles buried under a hydrophobic polymer barrier. J Nanopart Res 14 (7):928

62. Carlson C, Hussain SM, Schrand AM, Braydich-Stolle LK, Hess KL, Jones RL, Schlager JJ (2008) Unique cellular interaction of silver nanoparticles: size-dependent generation of reactive oxygen species. J Phys Chem B 112(43):13608-13619. doi:10.1021/jp712087m

63. Nel AE, Madler L, Velegol D, Xia T, Hoek EM, Somasundaran P, Klaessig F, Castranova V, Thompson M (2009) Understanding biophysicochemical interactions at the nano-bio interface. Nat Mater 8(7):543-557. doi:10.1038/nmat2442

64. Berry CC, de la Fuente JM, Mullin M, Chu SW, Curtis AS (2007) Nuclear localization of HIV-1 tat functionalized gold nanoparticles. IEEE Trans Nanobioscience 6(4):262-269

65. Tiedemann D, Taylor U, Rehbock C, Jakobi J, Klein S, Kues WA, Barcikowski S, Rath D (2013) Reprotoxicity of gold, silver, and goldsilver alloy nanoparticles on mammalian gametes. Analyst. doi:10. 1039/c3an01463k 